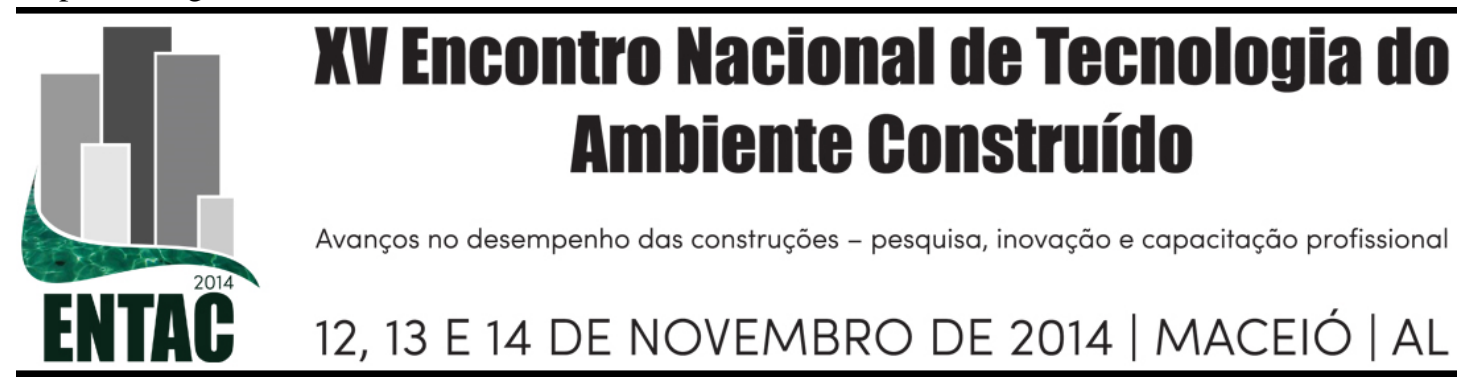

\title{
ESTUDO DO POTENCIAL DE CONTRIBUIÇÃO DA ENERGIA SOLAR FOTOVOLTAICA INTEGRADA A PRÉDIOS PÚBLICOS E INTERLIGADA À REDE ELÉTRICA NA REGIÃO SUL DO BRASIL EM PERÍODOS QUENTES \\ SALAMONI01, Isabel (1); DOS SANTOS02, Isis (2); ZOMER03, Clarissa (3); RÜTHER04, Ricardo (3)
}

(1) Universidade Federal de Pelotas, telefone, e-mail: isalamoni@ gmail.com (2) Universidade Federal de Santa Maria, e-mail: isisporto@gmail.com, (3) Universidade Federal de Santa Catarina, e-mail:

clazomer@gmail.com; rruther@gmail.com

\begin{abstract}
RESUMO
As elevadas temperaturas que atingiram o Brasil nos últimos anos, com destaque para os meses de Dezembro de 2013 e Fevereiro de 2014, acarretaram em recordes de consumo energético nos últimos anos, além de alguns apagões. Sendo assim, o consumo de energia elétrica e a instabilidade no fornecimento de energia também tendem a aumentar. Embora os reservatórios das hidrelétricas estejam em um nível maior do que o registrado no mesmo período do ano passado, as termelétricas continuam sendo acionadas. Da energia gerada atualmente, cerca de $13 \%$ vem das termelétricas, sobretudo nos horários de pico. A energia das térmicas chega a custar até cinco vezes mais que das hidrelétricas, além de serem altamente poluentes. Baseado neste contexto, a energia solar fotovoltaica (FV), que além de gerar eletricidade de forma distribuída, diferenciando-se da forma como se constitui o setor elétrico brasileiro, é inesgotável, silenciosa, estática, extremamente simples em sua operação, entra para poder contribuir com a crescente demanda energética de uma forma mais sustentável e estrategicamente eficiente. A geração fotovoltaica ocorre durante o dia, coincidindo com o pico de consumo dos setores comerciais e públicos. Os sistemas fotovoltaicos podem ser instalados próximos ao ponto de consumo, integrados às edificações e interligados à rede elétrica, evitando as perdas energéticas que ocorrem na transmissão e distribuição e auxiliando na redução do pico de carga. O trabalho faz parte de uma pesquisa não financiada, entre três instituições de ensino da região sul do Brasil. Através do estudo de área de cobertura disponível nas edificações comerciais e do consumo energético desses setores em três cidades da região sul do Brasil, pretende-se avaliar o potencial de contribuição da energia solar fotovoltaica na redução do consumo energético, por fonte convencional de energia, nos setores comerciais da região sul do Brasil inserido no contexto da Resolução Normativa 482/2012 da ANEEL, que estabelece as condições gerais para o acesso de microgeração e minigeração distribuída aos sistemas de distribuição de energia elétrica e para o sistema de compensação de energia elétrica.
\end{abstract}

Palavras-chave: BIPV, energia elétrica, energia solar fotovoltaica, pico de carga, eficiência energética.

\begin{abstract}
The high temperatures in Brazil last months, especially between December of 2013 and February of 2014, resulted in record of energy consumption and frequent blackouts. The trend, according to meteorologists is to get worst in the coming years. Sales of air conditioning equipment and fans increased $257 \%$ and $150 \%$ respectively, in 2014. Therefore, the energy consumption and the instability in energy supply also tend to increase. Currently about $13 \%$ of the energy generated comes from thermo power plants, particularly during the peak times. The thermal energy can cost up to five times that hydro energy and it is highly polluting. Based on this context, solar photovoltaic energy $(P V)$, in addition to generating electricity in a distributed way, that is different from how is the Brazilian electricity sector, is inexhaustible, silent, static, very simple in its operation, comes to contribute to the growing energy
\end{abstract}


demand in a more sustainable and strategically efficient way. The PV generation occurs during the day, coinciding with the peak consumption of commercial and public sectors. The systems are installed near to the point of consumption, integrated into buildings and connected to the grid, avoiding the energy losses that occurs in the transmission and distribution system and helping to reduce the peak loads. The work is part of a research not funded from three educational institutions in south of Brazil. Through the study of available roof areas in commercial buildings and energy consumption of these sectors in three cities in south of Brazil, the research aims to show the potential contribution of solar PV systems in reducing the energy consumption of conventional source of energy in the commercial sectors of Brazil region and to analyze the relation between the energy consumption and temperature. The study placed in the context Normative Resolution 482/2012 of ANEEL, which establishes the general conditions for the access of minigeneration and microgeneration to the electric power distribution systems and for the compensation system of energy.

Keywords: BIPV, electric energy, PV solar energy, energy load, energy efficiency.

\section{INTRODUÇÃO}

A rede elétrica brasileira é configurada na forma de uma super rede integrada ao longo de todo país. Esta rede possui fontes de geração centralizadas e muitas vezes distantes dos principais pontos de consumo (grandes centros urbanos) e não está preparada para suprir a crescente demanda energética. Os frequentes apagões observados nos períodos de intenso calor entre os meses de Dezembro de 2013 e Fevereiro de 2014 (EPE, 2014), corroboram com a instabilidade desta rede.

Minutos antes do apagão, que atingiu 13 estados brasileiros em Fevereiro de 2014, de acordo com o Operador Nacional do Sistema (ONS, 2014), a região Sul registrou recorde de energia demandada. Embora os reservatórios estivessem em um nível maior do que o registrado no mesmo período do ano passado, as termelétricas continuavam e continuam sendo acionadas, com o objetivo principal de poupar o volume de água, prevendo contínuo aumento da demanda.

A energia das térmicas chega a custar até cinco vezes mais que a das hidrelétricas, além de serem altamente poluentes. De acordo com o Ministério das Minas de Energia (MME, 2014), o custo do acionamento das termoelétricas nesse período de calor intenso será repassado ao consumidor final. Aproximadamente $13 \%$ da energia gerada atualmente no Brasil, é oriunda das termelétricas (MME - Balanço Energético Nacional, 2013), sobretudo nos horários de pico. Essa fonte, além de ser extremamente cara, é altamente poluente.

No Brasil, a demanda para consumidores comerciais é basicamente influenciada pelo uso de aparelhos de ar condicionado (Perez et al., 1987; Perez et al., 1997). Conforme Bailey et al., 1991;Jardim et al., 2008; Jardim et al., 2004;, 2005; Knob et al., 2004; Perez et al., 2003; Perez et al., 2001; Perez, Seals e Hering, 1996, nos períodos de verão a demanda em regiões comerciais é fortemente influenciada pelo uso intensivo de aparelhos de ar condicionado. Dessa forma, para esse perfil de consumidores o pico de demanda é diurno, coincidindo com períodos de intensa radiação solar (Lamberts et.al., 2014). Além da concomitância horária, a geração fotovoltaica e o condicionamento de ar para refrigeração também possuem concomitância anual, ou seja, no verão, quando há maior radiação (Basquera et. al., 2013), também há maior consumo de energia, e no inverno com menor radiação também há menor consumo de energia para refrigeração.

A opção de geração energética na própria edificação, a exemplo dos sistemas solares fotovoltaicos (FV), sobrepondo aos elementos construtivos ou até mesmo substituindoos, tem sido altamente incentivada por programas de certificação ambiental de edifícios. $\mathrm{O}$ crescimento do mercado FV trouxe esta tecnologia para o presente, sendo atualmente 
uma fonte consolidada e disponível comercialmente (IEA, 2010), o que em grande parte deve-se à utilização da tecnologia FV junto às edificações.

Os sistemas FV podem ser instalados próximos ao ponto de consumo, integrados à edificação e interligados à rede elétrica, evitando as perdas que ocorrem na transmissão e na distribuição e auxiliando na redução do pico de carga. Em um país com as dimensões do Brasil (8,5 milhões de $\mathrm{km}^{2}$ ), a infraestrutura de linhas de transmissão e distribuição, bem como as perdas de energia associadas, não são desprezíveis e devem ser consideradas.

Além disso, pode ser atribuída à tecnologia fotovoltaica sazonalidade equivalente com a geração hidroelétrica, ambas participando de uma rede elétrica inteligente. As redes inteligentes são aquelas que permitem o gerenciamento de vários pequenos geradores, mesmo em longas distâncias. Estas redes também controlam as flutuações na demanda e a sazonalidade da geração, priorizando a injeção na rede dos minigeradores fotovoltaicos descentralizados que utilizam uma fonte alternativa, e controlando a geração base das grandes centrais (NAIR e ZHANG, 2009). No caso do Brasil, a rede inteligente disponibilizaria nas horas de sol a geração fotovoltaica, aliviando a geração das hidrelétricas, e assim acumulando água no reservatório para geração posterior.

Inserido no contexto da Resolução Normativa 482/2012 da ANEEL, que estabelece as condições gerais para o acesso de microgeração e minigeração distribuída aos sistemas de distribuição de energia elétrica e para o sistema de compensação de energia elétrica, o presente artigo tem por finalidade analisar o impacto do consumo energético em três edificações públicas hospitalares do Brasil, localizadas nas cidades de Santa Maria -RS, Pelotas -RS e Florianópolis - SC, em função das mudanças de temperatura ao longo dos anos, bem como o potencial de geração de energia solar fotovoltaica (FV) em diferentes cidades do Sul do Brasil.

\section{CARACTERIZAÇÃO DAS CIDADES E DAS EDIFICAÇÕES}

\subsection{Cidades Analisadas}

Para o desenvolvimento deste estudo foram escolhidas três cidades da região sul do Brasil, que foi a região que apresentou os mais elevados consumos energéticos em Fevereiro de 2014 (EPE 2014). As cidades em questão, embora com algumas características climáticas diferentes, apresentam médias de radiação solar com pouca variação entre si.

A cidade de Santa Maria apresenta um clima do tipo subtropical úmido. Nos dias mais quentes do verão, as temperaturas máximas podem ultrapassar os $30^{\circ} \mathrm{C}$. Por outro lado, nos meses de outono, inverno, e no início da primavera, os dias mais frios podem apresentar mínimas em torno ou mesmo abaixo de $0^{\circ} \mathrm{C}$ (entre $0^{\circ} \mathrm{C}$ e $-4^{\circ} \mathrm{C}$ ), e máximas abaixo de $12^{\circ} \mathrm{C}$. A temperatura média anual da área urbana é de $19^{\circ} \mathrm{C}$. (INMET, 2014). A média anual de radiação solar global horizontal é de $4,83 \mathrm{kWh} / \mathrm{m}^{2} /$ dia (SWERA, 2015), valor $4 \%$ acima da média da cidade de Pelotas e 6,5\% acima da média da cidade de Florianópolis.

A cidade de Pelotas, assim como Santa Maria, apresenta um clima subtropical úmido. O comportamento climático segue o da cidade de Santa Maria com extremos de temperatura, tanto para os meses de verão, quanto para os meses de inverno. Os verões apresentam temperaturas máximas entre 34 e $36^{\circ} \mathrm{C}$, enquanto os invernos são relativamente frios, com temperaturas mínimas entre -2 e $0^{\circ} \mathrm{C}$. A temperatura média 
anual da área urbana é de $17,5^{\circ} \mathrm{C}$. (INMET, 2014). A média anual de radiação solar global horizontal é de 4,63 kWh/m²/dia (SWERA, 2015).

A cidade de Florianópolis apresenta as características climáticas inerentes ao litoral sulbrasileiro. As estações do ano são bem caracterizadas. $\mathrm{O}$ verão e o inverno são bem definidos, sendo o outono e primavera de características semelhantes. A média das máximas do mês mais quente varia de 26 e $31^{\circ} \mathrm{C}$ e a média das mínimas do mês mais frio, de 7,5 a $12{ }^{\circ} \mathrm{C}$. A temperatura média anual está em torno de $21^{\circ} \mathrm{C}$ (INMET, 2014). A média anual de radiação solar global horizontal é de $4,52 \mathrm{kWh} / \mathrm{m}^{2} /$ dia (SWERA, 2015).

Embora a cidade de Florianópolis apresente médias de temperatura mais elevadas que as outras duas cidades, ela apresenta média anual de radiação solar inferior.

\subsection{Edificações Analisadas}

Foram analisadas três edificações públicas com o mesmo uso para cada cidade. Essas edificações correspondem aos Hospitais Universitários vinculados às Universidades Federais destas cidades.

Na Figura 1 é apresentado o Hospital Universitário da Universidade Federal de Santa Maria (UFSM), localizado na cidade de Santa Maria -RS. Na Figura 2 é apresentado o Hospital Escola da Universidade Federal de Pelotas (UFPel), localizado na cidade de Pelotas -RS e na Figura 3 é apresentado o Hospital Universitário da Universidade Federal de Santa Catarina (UFSC) na cidade de Florianópolis - SC.

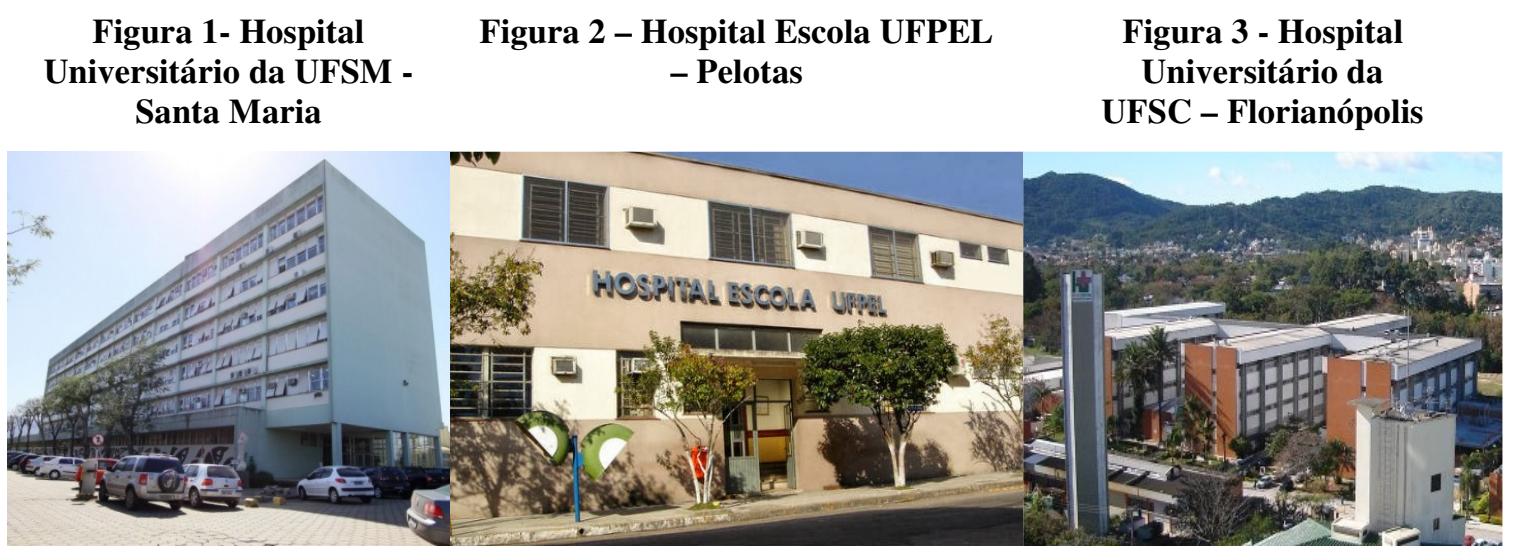

As três edificações apresentam pouca inclinação nas suas coberturas e estão parcialmente livres do sombreamento provocado por outras edificações do entorno, tendo em vista, principalmente, o fato de que elas são os prédios mais elevados desse entorno. Os três prédios estudados possuem uso durante 24 horas por dia.

\section{METODOLOGIA}

Primeiramente foram obtidos os dados de consumo energético mensais de cada edificação para um período de 24 meses. Foi computada para cada um desses meses a média de temperatura mensal em cada cidade. Foi observada e evolução dos dados de consumo com relação às temperaturas mensais de cada cidade, principalmente no mês Janeiro.

Para cada uma das edificações foi utilizada a mesma metodologia e banco de dados de radiação solar. Foi calculado o potencial de geração de energia solar fotovoltaica, partindo do princípio que toda a área de cobertura das edificações fosse coberta com 
módulo solar. Foi considerado um percentual de $20 \%$ da área de cobertura para espaçamento entre os módulos e perfis. Sendo assim, a área útil de cobertura considerada para a base de cálculo foi $80 \%$ da área total. Foram desconsideradas do cálculo as áreas sombreadas por outras edificações. Adotou-se como base uma tecnologia de módulo fotovoltaico com eficiência de $16 \%$, um valor bastante comum entre os módulos disponíveis comercialmente (GREEN et al., 2013).

Todas as edificações apresentam coberturas com pouca inclinação, por este motivo, foram considerados os módulos horizontais, ou seja, sem inclinação e desvio azimutal. Dessa forma os dados de radiação solar utilizados para os cálculos foram dados de radiação solar global horizontal, obtidos através do banco de dados do SWERA. Para cada cidade foram utilizados os seus respectivos dados de radiação.

O cálculo de geração de energia solar FV foi calculado de acordo com a Equação 1.

$$
\mathrm{G}=\mathrm{A} * \mathrm{E}_{\mathrm{FF}} * \mathrm{H}_{\mathrm{HOR}} * \mathrm{n} * \mathrm{R}
$$

onde, $\mathrm{G}=$ energia solar FV (G) em kWh/mês;

$\mathrm{A}=$ área útil de cobertura disponível em $\mathrm{m}^{2}$;

$\mathrm{E}_{\mathrm{FF}=}$ eficiência do módulo solar FV em \%;

$\mathrm{H}_{\mathrm{HOR}}=$ irradiação solar global horizontal em $\mathrm{kWh} / \mathrm{m}^{2} /$ dia;

$\mathrm{n}=$ os dias de cada mês;

$\mathrm{R}=$ rendimento do sistema em $\%$.

Em função do potencial de geração de energia solar FV que cada edificação apresenta foi calculado o percentual de suprimento do consumo de energia convencional de cada edifício hospitalar e analisada a contribuição na redução da curva de carga mensal.

\section{ANÁLISE DOS RESULTADOS}

A Tabela 1 apresenta os dados referentes à média mensal de temperatura para cada uma das cidades analisadas, bem como os valores de consumo mensal para cada edificação.

De acordo com esses dados, é possível observar que no mês de maior média de temperatura (Janeiro) o consumo aumentou entre os anos de 2012 e 2014 . Na cidade de Florianópolis, o consumo de Janeiro de 2012 foi maior do que o constatado em Janeiro de 2013, porém o consumo de Janeiro de 2014 foi recorde nos três casos estudados.

É possível constatar que o consumo energético vem aumentando, porém não é possível afirmar neste estudo que isso esteja diretamente relacionado ao aumento de temperatura, já que muitos outros fatores podem contribuir para elevar a demanda energética, como número de usuários e inserção de novos equipamentos, por exemplo. Assim este trabalho busca apenas relacionar a demanda energética crescente com a radiação solar disponível e o consequente potencial de geração energética das três cidades analisadas. 
Tabela 1 - Irradiação solar global horizontal de Santa Maria (RS), Pelotas (RS) e Florianópolis (SC)

\begin{tabular}{|l|c|c|c|c|c|c|}
\hline & \multicolumn{2}{|c|}{ HU Santa Maria } & \multicolumn{2}{c|}{ Hospital Escola Pelotas } & \multicolumn{2}{c|}{ HU Florianópolis } \\
\hline Meses & $\begin{array}{c}\text { Temperatura } \\
{ }^{\circ} \mathrm{C}\end{array}$ & $\begin{array}{c}\text { Consumo } \\
\mathrm{kWh} / \mathrm{mês}\end{array}$ & $\begin{array}{c}\text { Temperatura } \\
{ }^{\circ} \mathrm{C}\end{array}$ & $\begin{array}{c}\text { Consumo } \\
\mathrm{kWh} / \mathrm{mês}\end{array}$ & $\begin{array}{c}\text { Temperatura } \\
{ }^{\circ} \mathrm{C}\end{array}$ & $\begin{array}{c}\text { Consumo } \\
\mathrm{kWh} / \mathrm{mês}\end{array}$ \\
\hline Jan/12 & 33 & $\mathbf{3 6 1 . 0 4 4}$ & 28 & $\mathbf{5 6 . 5 7 5}$ & 28 & $\mathbf{5 2 8 . 9 4 7}$ \\
\hline Fev/12 & 33 & 397.894 & 30 & 57.749 & 30 & 511.192 \\
\hline Mar/12 & 30 & $\mathrm{ND}$ & 28 & 69.995 & 29 & 500.473 \\
\hline Abr/12 & 25 & 376.081 & 24 & 63.891 & 26 & 413.675 \\
\hline Mai/12 & 24 & 300.745 & 24 & 45.602 & 25 & 395.354 \\
\hline Jun/12 & 20 & 276.683 & 21 & 46.993 & 22 & 436.581 \\
\hline Jul/12 & 18 & 284.634 & 17 & 45.123 & 21 & 373.241 \\
\hline Ago/12 & 25 & 310.797 & 23 & 52.493 & 23 & 357.488 \\
\hline Set/12 & 24 & 286.937 & 21 & 47.332 & 24 & 392.412 \\
\hline Nov/12 & 30 & 280.396 & 27 & 45.446 & 27 & 472.280 \\
\hline Dez/12 & 31 & 387.573 & 29 & 64.226 & 29 & 514.820 \\
\hline Jan/13 & 30 & $\mathbf{4 0 4 . 9 9 2}$ & 27 & $\mathbf{7 0 . 8 2 0}$ & 29 & $\mathbf{5 0 7 . 9 7 9}$ \\
\hline Fev/13 & 29 & 392.387 & 28 & 73.948 & 30 & 513.103 \\
\hline Mar/13 & 27 & 404.982 & 26 & 59.425 & 27 & 429.233 \\
\hline Abr/13 & 26 & 297.161 & 24 & 54.189 & 27 & 423.016 \\
\hline Mai/13 & 21 & 290.257 & 21 & 52.332 & 24 & 363.443 \\
\hline Jun/13 & 19 & 289.125 & 18 & 47.757 & 22 & 340.233 \\
\hline Jul/13 & 20 & 295.300 & 18 & 42.785 & 21 & 362.216 \\
\hline Ago/13 & 19 & 304.374 & 17 & 51.299 & 21 & 350.672 \\
\hline Set/13 & 23 & 319.015 & 21 & 53.453 & 23 & 349.957 \\
\hline Out/13 & 26 & 297.626 & 22 & 43.030 & 24 & 388.524 \\
\hline Nov/13 & 29 & 310.272 & 24 & 46.659 & 26 & 411.922 \\
\hline Dez/13 & 32 & 376.633 & 26 & 50.829 & 29 & 465.281 \\
\hline Jan/14 & 33 & $\mathbf{4 3 5 . 5 3 9}$ & 31 & $\mathbf{8 2 . 8 8 2}$ & 31 & $\mathbf{5 4 0 . 6 6 6}$ \\
\hline Média & $\mathbf{2 6 , 1}$ & & $\mathbf{2 3 , 9}$ & & $\mathbf{2 5 , 7}$ & \\
\hline & & & & & & \\
\hline
\end{tabular}

De acordo com as médias de irradiação solar, a cidade de Santa Maria (média de temperatura mais elevada) apresenta a maior média de irradiação solar, seguida da cidade de Pelotas (menor média de temperatura anual do que a cidade de Florianópolis) e por fim, da cidade de Florianópolis. Esses valores não diferem muito entre si, na média geral, fazendo com que o comportamento de geração anual seja semelhante.

Com relação à geração de energia solar fotovoltaica, nenhuma edificação apresentou área de cobertura disponível para a instalação do sistema solar FV de forma a suprir toda a sua demanda energética. Mesmo que fosse utilizado um módulo mais eficiente, em torno de $20 \%$, ainda não supriria $100 \%$ da demanda das edificações. Isso se justifica pelo fato de a grande maioria das edificações públicas serem grandes consumidoras de energia e apresentarem pouca área de cobertura disponível para a implantação do sistema solar FV.

As três cidades apresentam variações climáticas diferentes e médias anuais de temperatura também. A cidade de Santa Maria apresenta a maior média anual de temperatura, seguida da cidade de Florianópolis. Porém, quando se analisa os dados de irradiação solar, apresentados na Figura 4, é possível constatar que elevadas temperaturas não resultam necessariamente de elevados índices de radiação solar. 


\section{Figura 4- Irradiação solar global horizontal de Santa Maria (RS), Pelotas (RS) e Florianópolis (SC)}

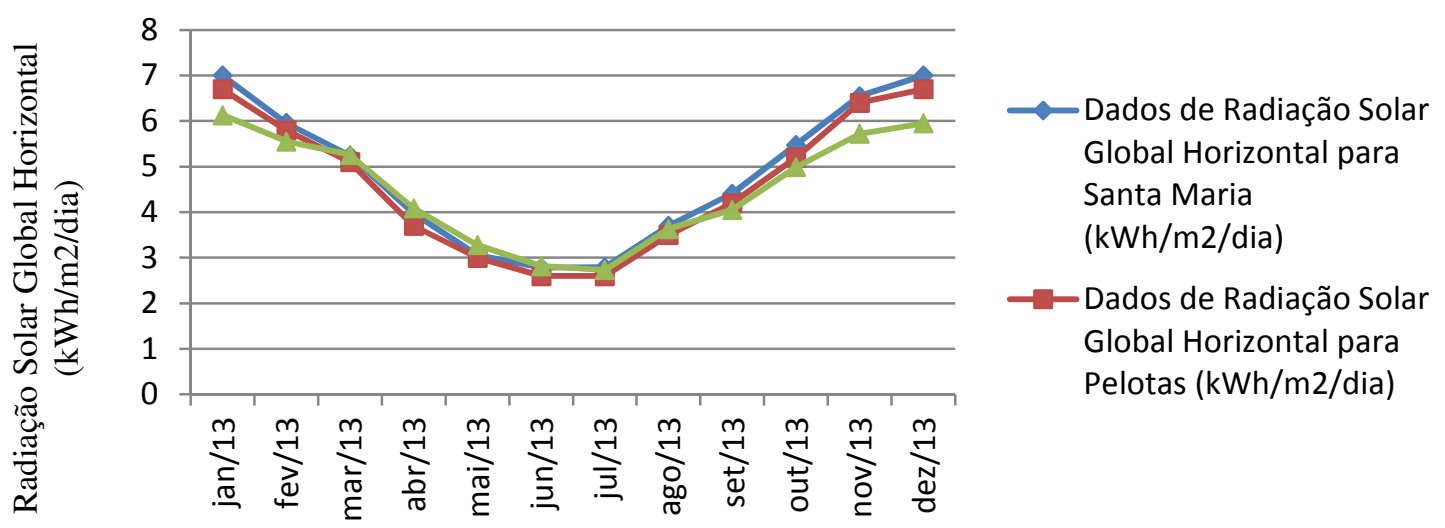

A análise da demanda de cada edificação e da geração fotovoltaica possível correspondente é apresentada nas Figuras 5, 6 e 7. Cada figura apresenta três diferentes curvas: a curva de consumo energético, a curva de geração de energia solar FV e a curva de consumo menos geração de energia solar FV.

Na Figura 5, relacionada ao Hospital de Santa Maria, é possível observar que o sistema de energia solar FV apresentaria uma contribuição de $70 \%$ no suprimento da demanda no mês de Novembro (máxima contribuição) e no pior caso esse percentual seria de $32 \%$ nos meses de Junho e Julho (piores índices de irradiação solar). Neste caso com a contribuição da energia solar FV, haveria uma modificação no perfil da curva de consumo mensal.

Figura 5 - Consumo de energia, geração energética e curva de geração com a contribuição FV para Santa Maria

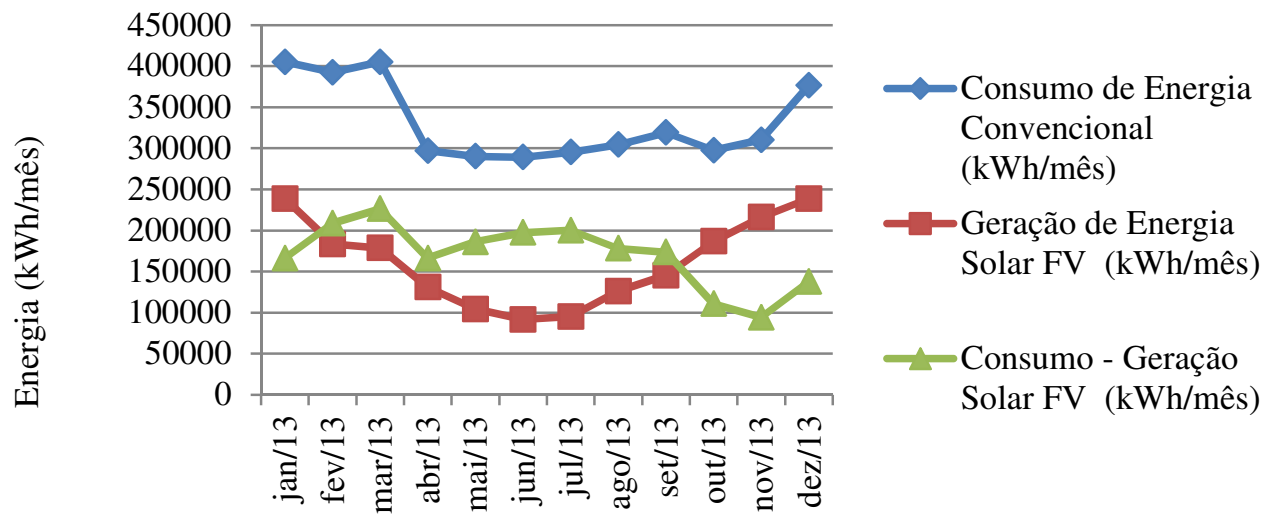

A Figura 6 apresenta os dados do Hospital Escola de Pelotas. Esta edificação apresentaria uma contribuição de $47 \%$ no suprimento da demanda nos mês de Novembro e Dezembro (maior contribuição), e esse percentual seria de $19 \%$ no mês de Junho (menor contribuição). Neste caso, não havia alteração no perfil da curva de carga, apenas haveria a redução do pico de consumo. 
Figura 6 - Consumo de energia, geração energética e curva de geração com a contribuição FV para Pelotas

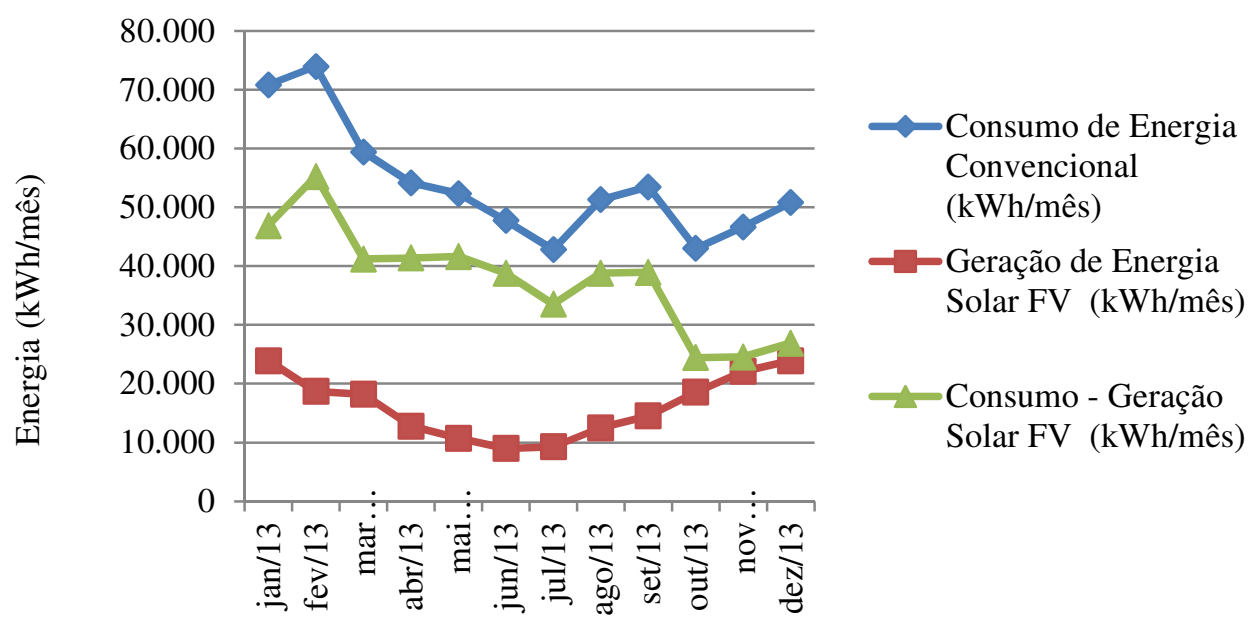

A cidade de Santa Maria, assim como a cidade de Pelotas, por apresentar dois extremos climáticos (verão e inverno) possui uma característica específica, pois não podemos dizer que neste caso a demanda energética acompanha a radiação solar, pois nos meses de inverno, com menor radiação, ainda há alto consumo energético. Em ambas as cidades, nos meses de inverno há consumo de aparelhos condicionadores de ar para o ciclo reverso (aquecimento), o que não acontece para a cidade de Florianópolis. Como já demonstraram alguns pesquisadores (Basquera et. al, 2013), mesmo a diminuição da temperatura dos painéis no inverno (que mantém sua eficiência) e o aumento da temperatura no verão (que diminuem sua eficiência) não promovem diferenças significativas na geração. A disponibilidade de radiação é que altera significativamente os níveis de geração energética.

A Figura 7 apresenta os dados do Hospital Universitário de Florianópolis. Pode-se observar que a curva de consumo segue a curva de geração de energia solar FV, ou seja, quanto maior a quantidade de irradiação disponível, maior o consumo energético. Isso pode também ser justificado pelo fato de não haver a necessidade de utilização dos sistemas de aquecimento artificial para o período de inverno.

Figura 7 - Consumo de energia, geração energética e curva de geração com a contribuição FV para Florianópolis

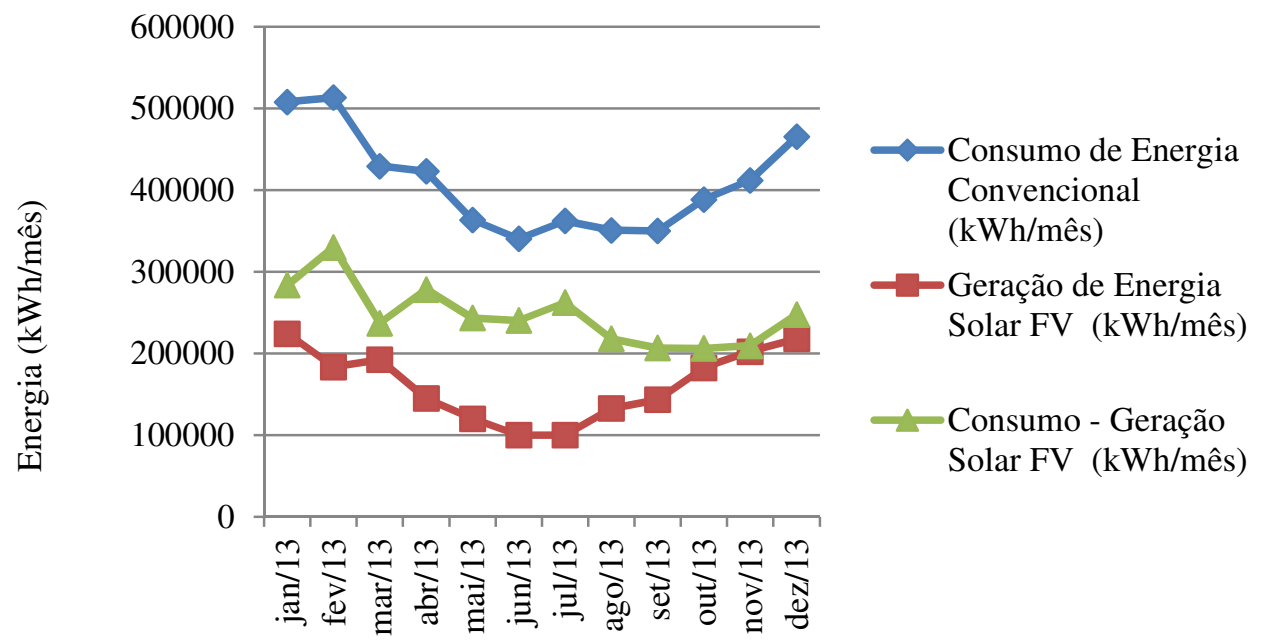


Para Florianópolis, o sistema fotovoltaico apresentaria uma contribuição de $49 \%$ no suprimento da demanda nos mês de Novembro (maior contribuição), e de $28 \%$ no mês de Julho (menor contribuição). Neste caso, assim como no Hospital Escola de Pelotas não havia alteração no perfil da curva de carga, apenas haveria a redução do pico de consumo.

\section{CONCLUSÕES}

A demanda energética vem aumentando continuamente a nível mundial. Esse fator, além de impactar significativamente no meio ambiente, gera uma instabilidade no setor energético. No Brasil, é nítida a fragilidade de um sistema de geração de energia centralizado e tendo $75 \%$ de sua matriz baseada na mesma fonte energética, neste caso, na fonte hídrica.

Aumentar a oferta de energia com base em fontes renováveis, no caso deste estudo a solar fotovoltaica, bem como a eficiência energética das edificações, passa a ser uma alternativa frente a essa problemática.

Os casos apresentados mostram que nenhuma das edificações possui área útil de cobertura suficiente para que a geração de energia solar FV suprisse $100 \%$ da demanda energética, porém os sistemas auxiliariam significativamente para aumentar a estabilidade do sistema e para a redução da curva de carga.

As três cidades se comportam de forma semelhante no que diz respeito à média anual de radiação solar; quando se analisa a geração mês a mês a cidade de Santa Maria apresenta um maior potencial de geração. O Hospital Universitário de Santa Maria foi o que obteve os melhores resultados em termos de geração e de percentual no suprimento de energia, podendo auxiliar, no melhor caso, com $70 \%$ no suprimento da demanda.

Foi possível constar que nos três casos os dados de consumo energético aumentaram no último ano no mês de Janeiro, período que também ocorrem os mais elevados índices de irradiação solar.

De acordo com os dados de temperatura, não se pode constatar a influência direta da elevação desta com o aumento do consumo energético, pelo menos no que diz respeito aos parâmetros analisados neste trabalho. Neste caso específico, o que foi possível constatar é que elevadas temperaturas, não necessariamente resultam em maiores índices de irradiação solar. Outra constatação importante é de que as cidades de Santa Maria e Pelotas não possuem curva de consumo seguindo a curva de radiação solar. Pelo fato de que essas cidades apresentam dois extremos climáticos, no período de inverno há consumo de aparelhos condicionadores de ar para o aquecimento. Isso faz com que também haja um elevado consumo energético nos meses de pouca irradiação solar e que a contribuição da geração fotovoltaica não seja padrão ao longo do ano.

Para uma análise mais precisa entre a influência do aumento da temperatura no aumento do consumo energético, seria necessário que houvesse uma avaliação dos hábitos de consumo e utilização de equipamentos por parte dos usuários.

\section{REFERÊNCIAS}

ANEEL - Agência Nacional de Energia Elétrica. Resolução Normativa 482/12. Disponível em: www.aneel.gov.br. Acesso em: Julho de 2014. 
BAILEY, B.;PEREZ, R.;DOTY, J.; ELSHOLZ, K.;STEWART, R.; HUSE, W. Early experiences of the 15 kW NMPC demand-side management photovoltaic project. Solar Cells, v.30, p.529-533, 1991.

BASQUERA JR., M. F. ; REITER, R. D. O. ; DUPONT, F. H. ; MICHELS, L. . Impacts of Local Climate Conditions on Photovoltaic Module Efficiency. In: 12th Brazilian Power Electronics Conference, 2013, Gramado. Anais do 12th Brazilian Power Electronics Conference, 2013. v. 1. p. 533537.

EPE - Empresa de Pesquisa Energética. Acessado em: www.epe.gov.br.

GREEN, M. A.; EMERY, K.; HISHIKAWA, Y.; WARTA, W.; DUNLOP, E. D. Solar cell efficiency tables ( version 41 ). , , n. version 41, p. 1-11, 2013.

IEA - Internacional Energy Agency. Disponível em: http://www.iea.org/. Acesso em: Julho de 2014.

INMET - Instituto Nacional de Meteorologia. Disponível em: www.inmet.gov.br. Acesso em: Julho de 2014.

JARDIM, C.;RÜTHER, R.;SALAMONI, I.;SOUZA, T. D.;REBECHI, S.; KNOB, P. The strategic siting and the roofing area requirements of building-integrated photovoltaic solar energy generators in urban areas in Brazil. Energy and Buildings, v.40, 2008.

JARDIM, C.;SAlAMONI, I.;RÜTHER, R.;KNOB, P.; DINIZ, A. S. C. O Potencial dos Sistemas Fotovoltaicos Interligados à Rede Elétrica em Áreas Urbanas: Dois Estudos de Caso. In: X Congresso Brasileiro de Energia, 2004. Anais. Rio de Janeiro: COPPE/UFRJ, 2004.v.III. p. 1217-1230.

KNOB, P.;RÜTHER, R.;JARDIM, C.; BEYER, H. Investigating the peak demand reduction capability of PV: a case study in Florianópolis, South Brazil. In: 19th European Photovoltaic

Solar Energy Conference and Exhibition, 2004. Anais. Paris - France, 2004.v.p. 877-890

LAMBERTS, R., DUTRA, L., PEREIRA, F. O. R. Eficiencia energética na arquitetura. 3. ed. rev. São Paulo (SP): Pro-Livros, 2014. 366p.

MME - Ministério das Minas de Energia. Balanço Energético Nacional, 2013. Disponível em: www.mme.gov.br. Acesso em: Julho de 2014.

NAIR, Nirmal-Kumar C., ZHANG Lixi. SmartGrid: Future networks for New Zealand power systems incorporating distributed generation. Energy Policy 37, 2009.

ONS - Operador Nacional do Sistema. Acessado em: 15 de maio de 2014. Disponível em: www.ons.gov.br.

PEREIRA, E. B.; MARTINS, F. R.; ABREU, S. L.; RUTHER, R. Atlas Brasileiro de Energia Solar. São José dos Campos, Brazil: INPE, 2006.

PEREZ, R.; SEALS, R.; INEICHEN, P.; STEWART, R.; MENICUCCI, D. A new simplified version of the perez diffuse irradiance model for tilted surfaces. Solar Energy [S.I.], v. 39, n. 3, p. 221-231, 1987.

PEREZ, R.;SEALS, R.; ZELENKA, A. Comparing Satellite Remote Sensing and Ground Network Measurements for the Production of Site/Time Specific Irradiance Data. Solar Energy, v.60, p.89-96, 1997.

PEREZ, R.;LETENDRE, S.; HERIG, C. PV and Grid Reliability: Availability of PV Power During Capacity Shortfalls. In: Proceedings of the American Solar Energy Society - ASES Annual Conference, 2001. Anais. Washington - USA, 2001.v.p.

PEREZ, R.;HOFF, T.;HERIG, C.; SHAH, J. Maximizing PV Peak Shaving with Solar Load Control Validation of a Web-Based Economic Evalution Tool. Solar Energy, v.74, p.409-415, 2003.

PEREZ, R.;SEALS, R.; HERIG, C. Photovoltaics can add capacity to the utility grid. NREL - National Renewable Energy Laboratory. Golden - CO, 1996.

SWERA. Solar and Wind Energy Research Assessment. Disponível em: http://maps.nrel.gov/SWERA. Acesso em: Julho de 2014. 